\title{
Rise of Cytomegalovirus Antibodies in an Infectious-mononucleosis-like Syndrome after Transfusion
}

\author{
L. KÄÄRIÄINEN,* M.D. ; E. KLEMOLA,† M.D. ; J. PALOHEIMO,‡, M.D.
}

It is not very uncommon for a patient, a few weeks after open-heart surgery, to develop a disease which haematologically resembles infectious mononucleosis. Smith (1964) reviewed the most important literature on the subject and described nine additional cases. Since then Bastin et al. (1965) have recorded 14 cases. Some cases have been reported after surgery in connexion with which extracorporeal circulation has not been used (Bergström and Dahlström, 1957 ; Paloheimo and Halonen, 1965). The number of cases reported now amounts to at least 65 . The aetiology of the disease is obscure. The majority of authors regard a viral infection transmitted via blood transfusion as the most probable cause. A sensitivity reaction related to the use of perfusion apparatus has also been suggested as a cause of the syndrome. The clinical picture is fairly uniform. Fever usually lasts for two to three weeks; there is no exudative pharyngitis. The heterophil agglutination test is mostly negative.

It was found by Klemola and Kääriäinen (1965) that there is a significant rise in the titre of the complement-fixing antibodies to the cytomegalovirus in the course of disease usually included, on account of the haematological picture, under the name infectious mononucleosis. This disease differs from the common type of infectious mononucleosis in that the heterophil agglutination test is negative and there is no exudative pharyngitis or enlargement of the lymph nodes. As the clinical symptoms and the behaviour of the heterophil agglutination test in the syndrome reminiscent of infectious mononucleosis after surgery are similar to those in the cases previously reported (Klemola and Kääriäinen, 1965), the possibility must be considered that these diseases may be caused by the same aetiological agent. Below we report some observations which argue in favour of that supposition.

\section{Case 1}

A woman of 37 who had anaemia caused by metrorrhagia received, in connexion with curettage on 3 September 1965, 3 units (approximately $450 \mathrm{ml}$.) of fresh citrated blood (in plastic bags), and (approximately 11 September one more unit in connexion with total hysteron 11 September one more unit in because a slight tendency to bleed due to thrombopenia had been found earlier. In this case, as in the two following cases, the blood was not refrigerated; the interval between donation of blood and transfusion was less than four hours. The white-cell picture was normal at the time of the operation. The white-cell picture was normer 27 September-that is, 24 days after the first transfusion-the patient developed fever, which lasted for. 20 days. She was first treated at the Second Department of Gynaecology and Obstetrics and was later transferred to the Second Department of Medicine. Fever was the main symptom. There was Department of Medicine. Fever was the lymph nodes. There was nothing indicative of heart disease. The liver and spleen were not palpable. A maculopapular morbilliform rash was seen between the 11 th and 15 th days of fever. The white-blood-cell count (W.B.C.) on the ninth day of fever was 6,700/c.mm.; $63.5 \%$ * Lecturer in Virology, Department of Virology, University of Helsinki.

t Chief, Fourth Department, Aurora Hent of Medicine, University Central Hospital, Helsinki. were lymphecytes, and many of these were atypical, leading to suspicion of infectious mononucleosis.

The white-cell count rose later and was typical of infectious mononucleosis. The highest number of leucocytes was found on the 18th day of fever: $11,300 / \mathrm{c} . \mathrm{mm}$. (23\% neutrophils, $0.5 \%$ eosinophils, $0.5 \%$ basophils, $4 \%$ monocytes, $60 \%$ lymphocytes, $12 \%$ atypical lymphocytes). The Paul-Bunnell test was carried out four times with negative results. Acquired toxoplasmosis was excluded by complement-fixation and dye tests in the course of the disease. The highest E.S.R. was $37 \mathrm{~mm}$./hour. The maximal value for serum glutamic oxaloacetic transaminase was 81 units $/ \mathrm{ml}$. (according to Reitman and Frankel, 1957). Serum bilirubin and alkaline phosphatase were normal.

The Chart shows the rise in the titre of complement-fixing antibodies to the cytomegalovirus strain "Ad 169 " in the course of the disease. The virological methods have been described elsewhere (Klemola and Kääriäinen, 1965). Nine days after the onset of the disease the titre was 4, later rising to 128 . No rise in the titres of complement-fixing antibodies to numerous other viruses, herpes simplex included, could be demonstrated.

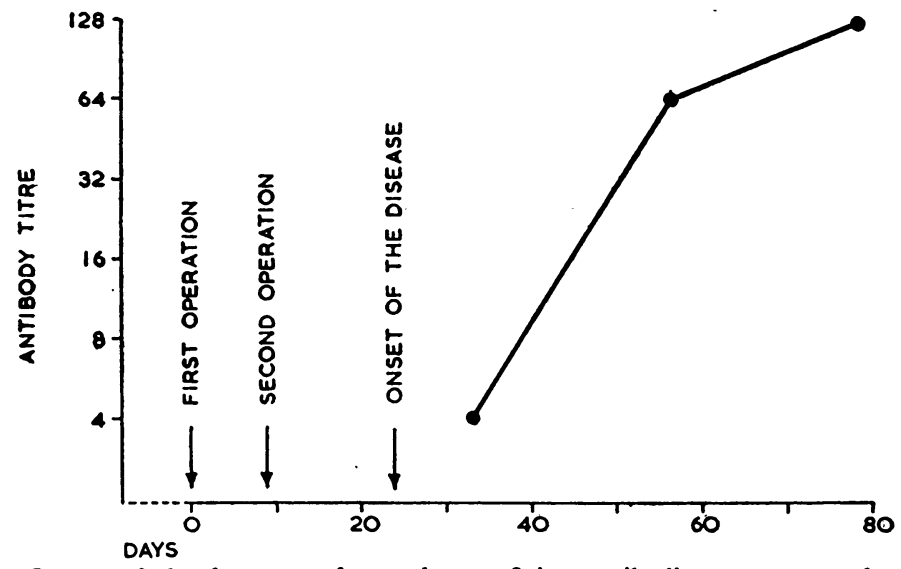

Course of development of complement-fixing antibodies to cytomegalovirus in a case of mononucleosis-like disease after transfusion of fresh blood in connexion with surgery.

All four blood donors were examined two months later after bloodtaking. Two of these, who had given blood in connexion with the first operation, had complement-fixing antibodies to the cytomegalovirus. The titres were of the same order-8 and 16-that were common in the control material of an earlier study (Klemola and Kääriäinen, 1965). The other two bload donars had no complement-fixing antibodies to the cytomegalovirus.

\section{Case 2}

A girl aged 15 with congenital heart disease was given fresh citrated blood during an attempt at heart surgery. Extracorporeal circulation was not used. A syndrome haematologically resembling infectious mononucleosis without a positive heterophil agglutination test developed four weeks later (Paloheimo and Halonen, 1965). The W.B.C. was 7,400/c.mm. on the fourth day of fever $(33.5 \%$ neutrophils, $0.5 \%$ eosinophils, $7.5 \%$ monocytes, $31.5 \%$ lymphocytes, $27 \%$ atypical lymphocytes). Complement-fixing antibodies to the cytomegalovirus were studied from the serum samples taken on the 9th and 23rd days from the onset of the fever (stored for one year at $-20^{\circ}$ C.) and one year afterwards. The first serum 
sample was anticomplementary, the titre of the second and third samples was 128 .

\section{Case 3}

A boy aged 16 had a syndrome resembling infectious mononucleosis without a positive heterophil agglutination test. The onset was four weeks after open-heart surgery with extracorporeal circulation. White cells on the ninth day of fever numbered $12,200 /$ c.mm. ( $33 \%$ neutrophils, $1 \%$ eosinophils, $1 \%$ basophils, $7 \%$ monocytes, $42 \%$ lymphocytes, $16 \%$ atypical lymphocytes). Complement-fixing antibodies to the cytomegalovirus were studied from a serum sample taken on the 11th day of fever (stored for eight months at $-20^{\circ} \mathrm{C}$.) and eight months afterwards. The titre for the first sample was 4 and for the second 64 .

\section{Discussion}

In Case 1 a syndrome resembling infectious mononucleosis developed after fresh blood transfusion in connexion with a gynaecological operation. In Case 2 a similar syndrome was seen after an attempt at heart surgery during which fresh blood was given but extracorporeal circulation was not used. The third case occurred after extracorporeal circulation. As regards the clinical picture and the result of the heterophil agglutination test, these cases resemble the cases of mononucleosis-like disease occurring in previously healthy persons without preceding surgery (Klemola and Kääriäinen, 1965). A further feature common to both groups is a significant rise in the titre of complement-fixing antibodies to the cytomegalovirus in the course of the disease, with the exception of Case 2, in which a high titre was found three weeks after the onset of disease. These observations make it appear likely that the cases reported above and in the previous paper are clinical manifestations of the same disease, "cytomegalovirus-mononucleosis." In not a single case among 400 patients with various acute infectious diseases, febrile type of PaulBunnell-negative infectious mononucleosis excluded, have we seen a significant rise of complement-fixing antibody titre to the cytomegalovirus in the course of the disease.

There must be particular reasons why the syndrome resembling infectious mononucleosis, when it occurs after surgery, is encountered almost exclusively after open-heart surgery. The observation that the disease begins two to four weeks after the operation indicates that it originates from the operation itself or from some procedure connected with it. The syndrome has not been reported with certainty after surgery when refrigerated citrated blood, stored for a length of time, or no blood, has been given. This strongly suggests that the transfusion of blood and the prior treatment of it are of essential importance. Fresh blood is commonly used for perfusion in open-heart surgery. However, the syndrome resembling infectious mononucleosis has also occurred when the blood is " taken into 'edgludate' anticoagulant on the day before operation and heparinized before use in the machine" (Smith, 1964). Transmission of the aetiological agent via the blood would afford a good explanation for the occurrence of the disease after surgery. In contrast to the agent of homologous serum jaundice, the aetiological agent responsible for this syndrome is apparently much more sensitive to storage. That the syndrome is encountered chiefly after open-heart surgery may be due to the fact that several blood donors are required in such cases. The administration of corticosteroids to such patients may also contribute to the breaking-out of the viral infection.

The incidence of the mononucleosis-like syndrome after open-heart surgery has been 3-11\% (Perillie and Glenn, 1962 ; Seaman and Starr, 1962 ; Wheeler et al., 1962 ; Smith, 1964). If the disease is transmitted principally via the blood the number of carriers among blood donors must be high. It is well known that post-natally acquired cytomegalovirus infections are common, though they are not apparent (Rowe et al., 1956 ; Weller et al., 1957 ; Carlström, 1965 ; Stern and Elek, 1965). It would be important to know whether the absence of complement-fixing antibodies to the cytomegalovirus is a precondition for contracting the mononucleosis-like disease after blood transfusion. Though this seems likely, there is also a possibility that a dormant cytomegalovirus infection can be reactivated by surgery and transfusion of fresh blood. The maintenance of virus in a latent form for many years after initial infection, with activation by diseases and treatments which depress the defence mechanisms of the host, is a feature characteristic of the herpes virus group, to which the cytomegalovirus belongs. It is also well to remember that the cytomegaloviruses isolated from man are not antigenically homogeneous, though they have a common complementfixing antigen. The strains differ in neutralization tests and may differ in their pathogenicity as well (Weller et al., 1960; Weller and Hanshaw, 1962).

\section{Summary}

A syndrome haematologically reminiscent of infectious mononucleosis developed in a patient after transfusion of fresh blood given in connexion with a gynaecological operation. The heterophil agglutination test was negative; there was no exudative pharyngitis and no enlargement of the lymph nodes. A significant rise in the titre of complement-fixing antibodies to the cytomegalovirus strain " Ad 169 " was demonstrable in the course of the disease. The results of antibody studies in two cases of a syndrome resembling infectious mononucleosis after heart surgery and fresh blood transfusions were compatible with the observations in the first-mentioned case.

The syndrome resembling infectious mononucleosis after open-heart surgery and after fresh blood transfusions may be a clinical manifestation of the same mononucleosis-like disease, "cytomegalovirus-mononucleosis" (Klemola and Kääriäinen, 1965).

The problems relating to the possible transmission of the disease via the blood are discussed.

We are indebted to Dr. H. Nevanlinna, chief of the Finnish Red Cross Blood Transfusion Service, and Dr. E. Ikkala, Second Department of Medicine, University Central Hospital, for their assistance. We wish to thank Professor P. I. Halonen, Professor I. Vartiainen, and Professor P. Vara, chiefs of the First and Second Department of Medicine and Second Department of Gynaecology and Obstetrics, University Central Hospital, Helsinki, who placed at our disposal the hospital records of the patients.

\section{Addendum}

In neutralization tests no antibodies were demonstrable against "Ad 169" and "Davis" strains in the first serum samples of all three cases. In Case 1 antibodies to "Ad 169 " and in Case 2 antibodies to "Davis" were found in. moderately high titres in serum samples taken seven weeks and one year after the onset of the disease, respectively.

Since this report was submitted for publication we have had an additional case of mononucleosis-like syndrome after open-heart surgery. A woman aged 28 contracted the disease three weeks after the operation. The highest W.B.C. was $18,600 /$ c.mm. (13\% neutrophils, $1.5 \%$ eosinophils, $1 \%$ basophils, $6 \%$ monocytes, $66 \%$ lymphocytes, $12.5 \%$ atypical lymphocytes). A few large atypical cells with massive intranuclear inclusions, characteristic of cytomegalic inclusion disease, were seen in the urinary sediment (Dr. A. Koivuniemi, Second Department of Pathology, University of Helsinki). The heterophil agglutination test was negative. No complement-fixing antibodies to the cytomegalovirus 
were found in the first two serum samples, taken before the surgery and on the seventh day from the onset of the fever. Later a gradual rise in the titre to high values was demonstrated. A cytopathic agent with the characteristics of a cytomegalovirus has been isolated from the urine in human fibroblast cultures.

\section{REFERENCES}

Bastin, R., Lapresle, C., and Dufrene, F. (1965). Presse méd., 73, 63. Bergström, I., and Dahlström, G. (1957). Acta tuberc. scand., 34, 132. Carlström, G. (1965). Acta paediat. (Uppsala), 54, 17.

Klemnla, E., and Kääriäinen, L. (1965). Brit. med. 7., 2, 1099.
Paloheimo, J. A., and Halonen, P. I. (1965). Duodecim (Helsinki), 81, 428.

Perillie, P. E., and Glenn, W. W. L. (1962). Yale F. Biol. Med., 34, 625. Reitman, S., and Frankel, S. (1957). Amer. F. clin. Path., 28, 56.

Rowe, W. P., Hartley, J. W., Waterman, S., Turner, H. C., and Huebner, R. J. (1956) Proc. Soc. Waterman, S., Turner, H. C.

Seaman, A. J., and Starr, A. (1962). Clin. Res. Proc., 10, 104.

Smith, D. R. (1964). Brit. med. F., 1, 945.

Stern, H., and Elek, S. D. (1965). Ұ. Hyg. (Lond.), 63, 79.

Weller, T. H., and Hanshaw, J. B. (1962). New Engl. F. Med., 266, 1233.

-

Macauley, J. C., Craig, J. M., and Wirth, P. (1957). Proc. Soc. exp. Biol. (N.Y.), 94, 4.

Wheeler, E. O., Turner, J. D., and Scannell, J. G. (1962). New Engl. 7. Med., 266, 454 .
The herbicidal activity has been investigated fully, and the substance is shown to be very rapidly absorbed into the aerial parts of plants, but its precise mode of action is unknown.

Contact with soil causes immediate absorption and complete inactivation. The substance is non-volatile, non-inflammable, non-explosive, and very soluble in water, giving an alkaline solution. Concentrated aqueous solutions will corrode mild stecl, galvanized iron, and aluminium.

Clark, McElligott, and Hurst (1966) have determined the toxicity of Paraquat for a number of animal species, and have described in some detail the pathological appearances which follow its administration by various routes in rats, mice, and rabbits. Lesions developing in the lungs are very unusual in type.

Up to July 1964 one case of poisoning in a child had occurred in Ireland. The present paper describes two further human fatalities in New Zealand. The two victims were a European aged 28 (Case 1) and a Maori aged 23 (Case 2). While in an intoxicated state at a party on 31 October 1964 the former ingested about half a glassful (4 oz.; $114 \mathrm{ml}$.) of a $20 \%$ solution of Paraquat in water from a bottle which previously had contained stout, while the latter was believed to have taken only a mouthful of the liquid, most of which was said to have been rejected immediately.

\section{Case 1}

On 1 November 1964 a European man aged 28 complained of a sore throat, dysphagia, epigastric pain, and possible haemoptysis but gave no history of vomiting. He had some diarrhoea on 2 and 3 November, and jaundice began on the $3 \mathrm{rd}$. He was admitted to the Lower Hutt Hospital on 4 November.

* Hutt Hospital, Lower Hutt, New Zealand.
On admission he was dehydrated, toxic, and moderately jaundiced, with excoriation of the lips, mouth, and fauces. He was apyrexic, with guarding in the upper abdomen, and had a decreased urinary output. The full blood count was normal. Initial liverfunction tests showed a total bilirubin of $8 \mathrm{mg} . / 100 \mathrm{ml}$., alkaline phosphatase 17.7 K.A. units, and thymol turbidity 11 units. These subsequently rose to 13,27 , and 27 respectively, with a decrease in serum proteins (albumin and globulin together). Initially his nonprotein nitrogen was $127 \mathrm{mg} . / 100 \mathrm{ml}$. and later 86 and $150 \mathrm{mg}$. Faeces were strongly positive for occult blood, and the urine showed a large amount of bilirubin but no increase in urobilinogen. His urinary albumin remained high. Schumm's test and ests for methaemoglobin were negative : serum S.G.O.T. 66 units, S.G.P.T. 160 units.

$X$-ray examination of the chest on 4 November showed nothing abnormal, but next day there was a widespread fine mottling suggestive of interstitial oedema. Changes on 7 November were even more marked, and at this stage the patient showed respiratory distress, despite a strict fluid balance and a reasonable urinary output (S.G. 1015 ) and electrolyte balance. An electrocardiogram (E.G.C.) suggested a conduction bundle defect of the heart, with associated toxic myocarditis.

Broadly treatment consisted of intravenous fluids, prophylactic penicillin, and pethidine for pain. On one occasion mannitol was given intravenously, to induce diuresis in an effort to reduce the pulmonary oedema. The effort was not successful. The patient died on 7 November, exactly one week after taking Paraquat.

Post-mortem Examination.-The pleural cavity contained slight blood-stained effusion. The mucous membrane of the larynx, trachea, and bronchi was slightly inflamed and thick mucus was present. The lungs were voluminous and solid, with haemorrhages and oedema. Histologically congestion and haemorrhages were conspicuous, and oedema fluid in some alveoli contained much fibrin. Much of the lung, however, was solid and airless from heavy proliferation in the alveolar walls and elsewhere of cells of fibroblastic type (cf. Clark et al., 1966). In a few places considerable proliferation of the epithelium of the terminal bronchi had led to the formation of small gland-like structures. Focal or diff use polymorphonuclear, mononuclear, or eosinophilic infiltration, and many macrophages, accompanied the other changes in some areas. The mouth was ulcerated, but not the ossophagus. The stomach was congested and areas of haemorrhage were apparent. The liver was enlarged by approximately one-half and was firm and yellow. Microscopically mid-zonal and centrilobular degeneration of the liver cells increased in severity, until, towards the centre of the lobules, the cells were on the verge of necrosis. Both kidneys were soft and swollen. Microscopically tubular degeneration was severe and ischaemic glomerular degeneration was seen, but probably the changes noted were at least in part due to post-mortem phenomena. 